\title{
Does extraocular muscle proprioception influence oculomotor control?
}

\author{
Clifford R Weir, Paul C Knox, Gordon N Dutton
}

Disorders of ocular motility are encountered on a regular basis within ophthalmic practice. They include a wide variety of conditions from non-paralytic strabismus commonly seen in paediatric clinics to acquired restrictive and paralytic conditions, which may be indicative of more serious underlying pathology. For an accurate diagnosis to be made an understanding of the basic mechanisms involved in oculomotor control is desirable.

Eye movements are mediated by a complex hierarchy of neuronal systems. While the final common pathway consists of the motor nuclei and associated structures in the brainstem, oculomotor behaviour is shaped by the cerebellum, the superior colliculus, the basal ganglia, and the cortical eye fields. ${ }^{1}$ In order to coordinate the movement of the eyes, a process vital for both vision and visually guided behaviour, these brain centres must "know" the direction in which the eyes are pointing.

If the eyes were fixed within the orbits then retinal (that is, visual) information would be sufficient to tell us where we are looking. However, the eyes, as well as the visual world, can and do move, and under these circumstances extraretinal (that is, non-visual) information is required to determine gaze direction. There are two broad hypotheses that seek to explain the source of this extraretinal information; while not mutually exclusive, they are often presented as alternatives. The "inflow" hypothesis holds that afferent signals from the effector muscles in the oculomotor system, the extraocular muscles (EOM), provide the necessary information about the positions of the eyes in the orbits and about movements of the eyes. This view can be attributed to Sherrington, ${ }^{2}$ although it fell out of favour, particularly in the 1960 s, when the role of muscle receptors in general came to be doubted (see Matthews ${ }^{3}$ for review). The outflow hypothesis, attributed to Helmholtz, ${ }^{4}$ holds that central monitoring of a copy of the motor command sent to the EOM (efference copy ${ }^{5}$ or corollary discharge ${ }^{6}$ ) provides the necessary extraretinal information. While in reality both afferent and efferent copy signals are probably involved, the relative contribution of each has been the subject of considerable debate for over a century. In this review we summarise the evidence concerning the existence of proprioceptive inflow from the EOM, and review recent physiological and clinical findings that it plays some part in oculomotor control.

\section{Evidence for the presence of inflow} INNERVATION

While the motor innervation of the EOM is well established, their sensory innervation has been the subject of considerable controversy. ${ }^{78}$ Two types of sensory receptor have been identified within the EOM - namely, muscle spindles $^{910}$ and myotendinous cylinders (palisade endings). ${ }^{11}$
Muscle spindles are located in the proximal and distal thirds of human extraocular muscles. ${ }^{12} 13$ Their structure differs from that of other species and also from spindles of other skeletal muscle. ${ }^{9}$ They consist of thin intrafusal fibres within a connective tissue capsule and lie in parallel with the extrafusal fibres. Two types of sensory ending are normally present in muscle spindles - namely, group I afferent fibres which arise from primary (annulospiral) endings and group II fibres which arise from secondary ("flower spray") endings. While spindle sensitivity is usually modulated by the gamma motor innervation, little is know about the role of gamma innervation in the EOM. Although EOM spindles are found in infant and elderly subjects at a density similar to that for spindles in hand and neck muscles, which suggests a role in fine motor control, ${ }^{10}{ }^{14}$ their proprioceptive capacity has been questioned. ${ }^{15}{ }^{16}$ Ludvigh $^{15}$ believed that "muscle spindles give rise to little, if any, acceptable information concerning the position of the eyes" while Ruskel1 ${ }^{16}$ found structural features within muscle spindles such as the presence of anomalous fibres within the connective tissue capsule, which he argued could jeopardise their proprioceptive function. However, structural considerations alone cannot settle the issue and are no replacement for empirical findings (see below). The other main sensory receptors of skeletal muscle, Golgi tendon organs, are not present in human extraocular muscles ${ }^{11} 17$ although they have been identified in other species such as the sheep ${ }^{18}$ and the monkey. ${ }^{19}$

Myotendinous cylinders (palisade endings) appear to be a class of muscle receptor unique to the EOM and are found within the distal myotendinous junction of the extraocular muscles both in humans and monkeys. ${ }^{1120}$ They consist of networks of fine neural filaments closely associated with the end of a single extrafusal muscle fibre and are surrounded by a thin capsule. ${ }^{21}$ Greater numbers of myotendinous cylinders are found within the horizontal compared with the vertical recti or oblique muscles. ${ }^{20}$ Given their intimate association with extrafusal fibres, a specialist role in monitoring EOM function has been suggested, ${ }^{11}$ in particular a response to active contraction of their associated muscle fibres. However, as no one has yet succeeded in recording from palisade afferent fibres, the precise information they transduce is not known. Nevertheless, in view of their location at the distal myotendinous junction, the very area at which the majority of strabismus procedures are performed, it is tempting to speculate that disrupting these receptors during surgery could lead to alterations in oculomotor control and affect the outcome of surgery.

PERIPHERAL PATHWAYS AND CENTRAL CONNECTIONS The primary afferent pathway from the EOM to central processing structures has also generated a degree of controversy. Animal studies have shown that afferent fibres 
travel for a variable distance with the motor cranial nerves (III, IV, and VI) before crossing to travel in the ophthalmic branch of the trigeminal nerve. ${ }^{22-24}$ The balance of the evidence indicates that the vast majority if not all the primary afferent cell bodies are located within the trigeminal ganglion in various species, including monkeys, ${ }^{25}$ cats, ${ }^{26}$ birds, ${ }^{27}$ and rabbits. ${ }^{28}$ Primary afferent fibres terminate in the ipsilateral spinal trigeminal nucleus in the $\mathrm{cat}^{29}$ and in the monkey, in which there is also a secondary projection to the cuneate nucleus. ${ }^{25}$ The effects of the stimulation of EOM afferent signals have been detected in a large number of visual and oculomotor structures including the cerebellum, ${ }^{30}$ the vestibular nuclei, ${ }^{31}$ the abducens nucleus, ${ }^{32}$ and the superior colliculus. ${ }^{33}$

\section{Function of extraocular muscle proprioception}

The evidence not only for the presence of sensory receptors within the EOM, but also for their capability of conveying afferent signals to all of the important structures involved in visual and oculomotor control has been outlined above. The next issue we have to consider is to what extent and in what ways do EOM afferent signals alter information processing in these structures? There is increasing evidence from experiments in both animals and humans that EOM afferent signals are important in three broad areas of visuomotor control. Firstly, oculomotor control, which will be discussed in more detail below. Secondly, the development and maintenance of normal binocular visual function (for reviews see Steinbach ${ }^{34}$ and Buisseret ${ }^{35}$ ), and, thirdly, in spatial localisation, by providing afferent information about the position of the eye within the orbit, which in turn helps to determine visual direction. ${ }^{34} 35$ The remainder of this article will consider the potential role of proprioception in oculomotor control specifically.

\section{Oculomotor control}

ANIMAL STUDIES

There is evidence derived from animal studies that proprioceptive input influences both gaze holding and gaze shifting systems. For example, EOM deafferentation of animals by sectioning the ophthalmic branch of the trigeminal nerve affects fixation stability in cats $^{36}$ and causes deviation of the eye position in lambs. ${ }^{37}$ Section of the III, IV, and VI cranial nerves of one eye in the cat, disrupting afferent feedback, alters the fixation stability of the contralateral eye in the dark. ${ }^{38}$ O'Keefe and Berkley ${ }^{39}$ demonstrated that in anaesthetised cats, retrobulbar injection of a paralytic drug reduced eye movements in both the ipsilateral treated eye and the contralateral untreated eye. They concluded that EOM afferent signals from extraocular muscles mediated this effect possibly by influencing the central motor command signal. Further studies have also shown that proprioception contributes to the maintenance of ocular alignment during fixation in monkeys. ${ }^{40}$

In addition to the stability of the eyes within the orbits, proprioception also modifies eye movements. For example, the conjugacy of saccadic eye movements in monkeys is impaired by deafferentation. ${ }^{40}$ There is considerable evidence that EOM afferent signals modify the processing of vestibular information and in so doing alter eye movements generated by the vestibular system. ${ }^{41}$ Removal of the proprioceptive input from extraocular muscles by sectioning the ophthalmic branch of the trigeminal nerve disrupts the slow phase and reduces the gain of the vestibulo-ocular reflex (VOR) in rabbits. ${ }^{28}{ }^{42}$ Manipulating EOM afferent signals by imposing movements on one eye modifies the output of the VOR of the contralateral eye in pigeons and indicates that such signals may be important in the moment to moment control of the VOR. ${ }^{43}$ These effects have been demonstrated not only in reduced experimental preparations, but also in the alert behaving animal. ${ }^{45}$ In addition, Kimura et $a l^{42}$ have shown that interrupting the EOM afferent pathway in rabbits modifies the gain and velocity of optokinetic nystagmus.

The timescale over which proprioceptive feedback might act upon the oculomotor control system in animals is, again, the subject of some debate. While it has been argued that it functions over the long term to bring about adaptive parametric adjustment of eye movements, ${ }^{40}$ much of the physiological evidence discussed above is suggestive of a more immediate effect ${ }^{44}$ (see also Knox et $a l^{46}$ ).

\section{HUMAN STUDIES}

Two main experimental methods have been described for studying the role of EOM afferent signals in human studies: vibration of the muscle tendon and passively moving the whole eye. Vibrating a muscle tendon is a recognised way of stimulating muscle spindles in particular ${ }^{47}$ and generates an afferent signal that is interpreted by the central nervous system as stretching of the muscle. This technique has been used specifically to induce EOM afferent signals. ${ }^{48}$ The second method involves passively moving an eye using a scleral contact lens held in place with gentle suction. This technique probably has the advantage of modifying the proprioceptive input from all the EOM simultaneously, ${ }^{49}$ although how closely the resultant afferent signal resembles that produced by voluntary contraction is unclear. Using these approaches, observations have been made in both normal subjects and patients that suggest a role for EOM afferent signals in the control of eye movements.

Gauthier et $a p^{50}$ demonstrated that after a period of passive deviation of one eye a change in phoria is observed which corresponds to the direction of the original deviation. For example, deviating the right eye temporally resulted in an increased exophoria, as measured by the Lancaster red-green dissociating test. This effect, which persisted for several minutes after the suction contact lens was removed, was quickly eliminated by binocular viewing. The authors suggested that the change in ocular alignment was due to an interaction between EOM afferent signals and central control mechanisms. Lennerstrand et $a \Gamma^{2}$ have shown, using single EOM vibration, that both the vertical and horizontal position of the non-stimulated eye could be modified depending on the EOM stimulated. For example, vibrating the inferior rectus muscle of one eye in normal subjects induced an upward movement of both eyes, while vibration of the lateral rectus muscle induced an abduction movement of the contralateral eye. The exact mechanism by which this occurs is unclear. However, direct interactions between afferent signals from individual EOM and the motor nuclei of synergistic and antagonist muscles are highly unlikely given the earlier discussion on the route of the afferent pathway. Interestingly, the response of exotropic subjects to vibration of the lateral rectus was opposite to that seen in normal subjects; an adduction movement was noted in the contralateral eye. This suggests an altered pattern of central processing of EOM afferent signals in these subjects.

Both saccades and smooth pursuit can also be modified by EOM proprioception. Saccadic eye movements, because of their short durations and high velocities, are usually considered to be ballistic - that is, ie not under feedback control. While visual feedback is certainly too slow for the control of individual saccades, EOM afferent signals might theoretically be involved. Using the single EOM vibration technique, the programming of memory guided saccades was shown to be influenced by altering EOM proprioception. ${ }^{53}$ Recently, Knox et $a l^{46}$ reported that 
impeding the movement of one eye using a scleral contact lens reduced the saccade amplitudes in the contralateral eye, an effect caused by a non-visual afferent signal, most likely arising from the EOM. The adaptive response of the smooth pursuit system to changes in target velocity has also been modified using proprioceptive feedback, ${ }^{54}$ and indeed smooth pursuit initiation is altered when the contralateral eye is impeded. ${ }^{55}$

It might be argued that all of these studies involve nonphysiological manipulations of EOM afferent feedback, thereby inducing aberrant interactions in the oculomotor control circuitry, which in turn leads to altered or degraded oculomotor behaviour. However, allied to the anatomical and structural findings discussed above, these results clearly indicate that EOM afferent signals can influence the control of eye movements.

This viewpoint is further strengthened by observations in patients, which suggest that EOM afferent signals may be important in the aetiology of certain oculomotor disorders. For example, studies in subjects with congenital strabismus have shown alterations in the morphology of EOM proprioceptors, such as smaller size and a disorganised structure. ${ }^{56}$ However, it is not possible to be sure whether these changes are the cause or the consequence of the strabismus and further studies are needed to confirm these findings. Mitsui ${ }^{57}$ has argued that EOM afferent signals are involved in the pathogenesis of both exotropia and esotropia. It was found that in exotropic patients, slight passive adduction of the non-deviated eye using forceps causes the deviating eye to straighten. This observation was termed the "magician's forceps phenomenon". The underlying cause of the exodeviation was believed to be abnormal proprioceptive input from the non-deviated eye, which caused excessive contraction of the lateral rectus of the contralateral, deviating eye. When the non-deviating eye was passively adducted the resultant stretch of the lateral rectus muscle modified the afferent input to the oculomotor centres which in turn influenced the position of the contralateral eye. Analogous observations could only be made in esotropic patients using electromyography. Although the interpretation of these observations has been questioned $^{35}$ they do suggest that an imbalance in EOM afferent information may affect oculomotor control.

Interestingly, modified EOM proprioception has been proposed as a factor in the aetiology and treatment of congenital nystagmus. Optican and $\mathrm{Zee}^{58}$ suggested that erroneous afferent feedback regarding eye velocity is important in the development of this form of nystagmus. In addition, Dell'Osso et $a t^{59}$ have recently reported damping of congenital nystagmus following staged tenotomy of all the EOM in an animal model. They suggest that this effect is due to an alteration in proprioceptive feedback from the EOM as a result of the tenotomy procedure. While acknowledging that such a procedure risks causing anterior segment ischaemia in humans, they argue that a modified procedure, consisting of bilateral medial rectus recession combined with bilateral lateral rectus tenotomy, may provide a potential surgical therapy for this condition.

The balance of the evidence is, therefore, that EOM afferent signals are not only available to oculomotor and visual control structures, but that they influence the processing of information in these structures, thereby modifying visuomotor behaviour. However, two key pieces of experimental evidence are often quoted as counter evidence to this proposition. The first comes from Keller and Robinson, ${ }^{60}$ who reported that in the monkey there is no monosynaptic stretch reflex in the oculomotor system. While recording from single units in the abducens nucleus, they found no alteration in firing rate when either the ipsilateral eye was moved by an external force, or when a self generated movement was impeded. However, it should be remembered that demonstrating that there is no direct ipsilateral feedback pathway onto the motor neurons is not the same as demonstrating that no feedback pathway exists. Guthrie et $a l^{61}$ provided the second key piece of evidence, by showing that monkeys in whom EOM afferent signals had been eliminated could still make accurate saccades. However, once again demonstrating that saccades can be executed accurately in the absence of EOM afferent feedback, is not equivalent to demonstrating that EOM afferent feedback plays no part when it is available. In addition, it may be that when the afferent pathway is damaged or degraded, or indeed manipulated, there is sufficient redundancy and flexibility to ensure that performance recovers (see Knox et $a l^{46}$ for further discussion of this point). This still leaves open the issue of the precise time course of modification. Ludvigh ${ }^{62}$ suggested that the mode of action was consistent with a long term adaptive effect in which afferent feedback induces modifications in efferent motor commands. As already noted, however, a number of key experimental results are actually more consistent with action on a far shorter timescale. This might be evidence for a fast adaptive process unique to the oculomotor system ${ }^{46}$ or even online control of individual oculomotor or visuomotor acts. The increasing awareness of EOM proprioception is reflected in a recently described theoretical model in which information derived from efference copy and afferent feedback are integrated, with both having a fundamental role in oculomotor control. ${ }^{63}$

\section{Conclusion}

Knowledge of the position of the eyes within the orbits is a prerequisite for coordinated eye movements, gaze shifts, and accurate visuomotor behaviour. Although vision itself, combined with central monitoring of outflowing neural discharge to the EOM, provides much of the required information, there is now considerable experimental and clinical evidence that inflowing proprioceptive signals from the EOM make a vital contribution. Animal and human studies have demonstrated that removing or manipulating EOM afferent input not only affects static eye position but can also modify smooth pursuit, saccades and the vestibulo-ocular reflex. A greater understanding of the role of proprioception in oculomotor control would be beneficial not only from a theoretical viewpoint but also in everyday clinical practice as strabismus surgery, a commonly performed procedure, involves manipulating areas of the extraocular muscles richly endowed with proprioceptors. Too little attention has been paid to the visual, oculomotor, and visuomotor sequelae of muscle surgery. Thus, little is known as to what effect, if any, different methods of handling these tissues might have on surgical success. Further studies are clearly required.

This work was supported by the Chief Scientist Office, Scottish Office. CLIFFORD R WEIR

Tennent Institute of Ophthalmology, Gartnavel General Hospital, Glasgow and Vision Sciences, Glasgow Caledonian University, Glasgow

PAUL C KNOX

Division of Orthoptics, University of Liverpool, Brownlow Hill, Liverpool

GORDON N DUTTON

Tennent Institute of Ophthalmology, Gartnavel General Hospital, Glasgow

Correspondence to: Dr Clifford R Weir, Tennent Institute of Ophthalmology, Gartnavel General Hospital, 1053 Great Western Road, Glasgow G12 0YN

1 Leigh RJ, Zee DS. The neurology of eye movements. 3rd ed. New York: Oxford University Press, 1999. 
2 Sherrington CS. Observations of the sensual role of the proprioceptive nerve supply of the extrinsic ocular muscles. Brain 1918;41:332-43.

3 Matthews PB. Where does Sherrington's "muscular sense" originate? Muscles, joints, corollary discharges? Annu Rev Neurosci 1982;5:189-218.

4 Helmholtz Hv. Handbuch der Physiologischen Optik. Leipzig: Voss, 1866 (translated by Southall JPC. A treatise on physiological optics. Vol 3. New York: Dover Publications Inc, 1962).

5 Holst Hv. Relations between the central nervous system and the peripheral organs. Br f Anim Behav 1954;2:89-94.

6 Sperry RW. Neural basis of the spontaneous optokinetic response produced by visual neural inversion. f Comp Physiol Psychol 1950;43:482-9.

7 Spencer RF, McNeer KW. The periphery:extraocular muscles and motor neurones. In: Carpenter RHS, ed. Eye movements. Vol 8. London: MacMillan Press, 1991

8 Bach-y-Rita P. Structural-functional correlations in eye muscle fibers. Eye muscle proprioception. In: Lennerstrand G, Bach-y-Rita P, eds. Basic mechanisms of ocular motility and their clinical implications. Oxford: Pergamon Press, 1975:91-111.

9 Ruskell GL. The fine structure of human extraocular muscle spindles and their potential proprioceptive capacity. F Anat 1989;167:199-214.

10 Lukas JR, Aigner M, Blumer R, et al. Number and distribution of neuromuscular spindles in human extraocular muscles. Invest Ophthalmol Vis Sci 1994;35:4317-27.

11 Richmond FJ, Johnston WS, Baker RS, et al. Palisade endings in human extraocular muscles. Invest Ophthalmol Vis Sci 1984;25:471-6.

12 Cooper S, Daniel PM. Muscle spindles in human extrinsic eye muscles. Brain 1949;72:1-24.

13 Merrillees NCR, Sunderland S, Hayhow W. Neuromuscular spindles in the extraocular muscles in man. Anat Rec 1950;108:23-30.

14 Blumer R, Lukas JR, Aigner M, et al. Fine structural analysis of extraocular muscle spindles of a two-year-old human infant. Invest Ophthalmol Vis Sci 1999;40:55-64

15 Ludvigh E. Possible role of proprioception in the extraocular muscles. Arch Ophthalmol 1952;48:436-41.

16 Ruskell GL. Extraocular muscle proprioceptors and proprioception. Prog Retin Eye Res 1999;18:269-91.

17 Sodi A, Corsi M, Faussone Pellegrini MS, et al. Fine structure of the receptors at the myotendinous junction of human extraocular muscles. Histol Histopath 1988;3:103-13.

18 Ruskell GL. Golgi tendon organs in the proximal tendon of sheep extraocular muscles. Anat Rec 1990;227:25-31.

19 Ruskell GL. The incidence and variety of Golgi tendon organs in extraocular muscles of the rhesus monkey. F Neurocytol 1979;8:639-53.

20 Ruskell GL. The fine structure of innervated myotendinous cylinders of extraocular muscles of rhesus monkeys. F Neurocytol 1978;7:693-708.

21 Alvarado-Mallart RM, Pincon-Raymond M. The palisade endings of cat extraocular muscles:a light and electron microscope study. Tissue Cell 1979;11:567-84

22 Cooper S, Daniel PM, Whitteridge D. Muscle spindles and other sensory endings in the extrinsic eye muscles; the physiology and anatomy of these receptors and their connexions with the brainstem. Brain 1955;78:564-83.

23 Batini C, Buisseret P, Buisseret-Delmas C. Trigeminal pathway of the extrinsic eye muscle afferents in cat. Brain Res 1975;85:74-8.

24 Gentle A, Ruskell G. Pathway of the primary afferent nerve fibres serving proprioception in monkey extraocular muscles. Ophthal Physiol Opt 1997;17:225-31.

25 Porter JD. Brainstem terminations of extraocular muscle primary afferent neurons in the monkey. 7 Comp Neurol 1986;247:133-43.

26 Porter JD, Spencer RF. Localization of morphology of cat extraocular muscle afferent neurones identified by retrograde transport of horseradish peroxidase. 7 Comp Neurol 1982;204:56-64.

27 Hayman MR, Donaldson JP, Donaldson IM. The primary afferent pathway of extraocular muscle proprioception in the pigeon. Neuroscience 1995;69: 671-83.

28 Kashii S, Matsui Y, Honda Y et al. The role of extraocular proprioception in vestibulo-ocular reflex of rabbits. Invest Ophthalmol Vis Sci 1989;30:225864.

29 Buisseret-Delmas C, Buisseret P. Central projections of extraocular muscle afferents in cat. Neurosci Lett 1990;109:48-53.

30 Baker R, Precht W, Llinas R. Mossy and climbing fiber projections of extraocular muscle afferents to the cerebellum. Brain Res 1972;38:440-5.

31 Buisseret-Delmas C, Epelbaum M, Buisseret P. The vestibular nuclei of the cat receive a primary afferent projection from receptors in extraocular muscles. Exp Brain Res 1990;81:654-8.

32 Donaldson IM, Knox PC. Afferent signals from pigeon extraocular muscles modify the vestibular responses of units in the abducens nucleus. Proc $R$ Soc Lond B Biol Sci 1991;244:233-9.

33 Abrahams VC, Rose PK. Projections of extraocular, neck muscle, and retinal afferents to superior colliculus in the cat:their connections to cells of origin of tectospinal tract. $₹$ Neurophysiol $1975 ; 38: 10-8$.

34 Steinbach MJ. Proprioceptive knowledge of eye position. Vis Res 1987;27:1737-44.
35 Buisseret P. Influence of extraocular muscle proprioception on vision Physiol Rev 1995;75:323-38.

36 Fiorentini A, Maffei L. Instability of the eye in the dark and proprioception. Nature 1977;269:330-1.

37 Pettorossi VE, Ferraresi A, Draicchio F, et al. Extraocular muscle proprioception and eye position. Acta Otolaryngol (Stockh) 1995;115:13740.

38 Magnin M, Salinger W, Kennedy H. Optokinetic response and visual suppression of the vestibulo-ocular reflex in the open loop condition in the cat. Vis Res 1986;26:653-60.

39 O'Keefe LP, Berkley MA. Binocular immobilization induced by paralysis of the extraocular muscles of one eye: evidence for an interocular proprioceptive mechanism. I Neurophysiol 1991;66:2022-33.

40 Lewis RF, Zee DS, Gaymard BM, et al. Extraocular muscle proprioception functions in the control of ocular alignment and eye movement conjugacy. f Neurophysiol 1994;72:1028-31

41 Knox PC, Donaldson IML. Extraocular muscle afferent signals and the vestibulo-ocular reflex. In: Delgado-Garcia JM, Godaux E, Vidal PP, eds. Information processing undelying gaze control . Oxford: Elsevier, 1994:30918.

42 Kimura M, Takeda T, Maekawa K. Contribution of eye muscle proprioception to velocity-response characteristics of eye moven

43 Knox PC, Donaldson IM. Afferent signals from the extraocular muscles of the pigeon modify the vestibulo-ocular reflex. Proc R Soc Lond B Biol Sci 1993;253:77-82.

44 Donaldson IM, Knox PC. Evidence for corrective effects of afferent signals from the extraocular muscles on single units in the pigeon vestibulooculomotor system. Exp Brain Res 1993;95:240-50.

45 Donaldson IML, Knox PC. Afferent signals from the extraocular muscles affect the gain of the horizontal vestibulo-ocular reflex in the alert pigeon. Vis Res 2000;40:1001-11.

46 Knox PC, Weir CR, Murphy P. Modification of visually guided saccades by a non-visual afferent feedback signal. Invest Ophthalmol Vis Sci 2000;(in press).

47 Goodwin GM, McCloskey DI, Matthews PBC. The contribution of muscle afferents to kinaesthesia shown by vibration induced illusions of movement and by the effects of paralysing joint afferents. Brain 1972;95:705-48.

48 Velay JL, Roll R, Lennerstrand G, et al. Eye proprioception and visual localization in humans: influence of ocular dominance and visual context. Vis Res 1994;34:2169-76.

49 Gauthier GM, Nommay D, Vercher JL. Ocular muscle proprioception and visual localization of targets in man. Brain 1990;113:1857-71.

50 Gauthier GM, Vercher JL, Zee DS. Changes in ocular alignment and pointing accuracy after sustained passive rotation of one eye. Vis Res 1994;34:2613-27.

51 Gauthier GM, Vercher JL, Blouin J. Egocentric visual target position and velocity coding: role of ocular muscle proprioception. Ann Biomed Eng 1995;23:423-35

52 Lennerstrand G, Tian S, Han Y. Effects of eye muscle proprioceptive activation on eye position in normal and exotropic subjects. Graefes Arch Clin Exp Ophthalmol 1997;235:63-9.

53 Allin F, Velay JL, Bouquerel A. Shift in saccadic direction induced in humans by proprioceptive manipulation:a comparison between memoryguided and visually guided saccades. Exp Brain Res 1996;110:473-81.

54 van Donkelaar P, Gauthier GM, Blouin J, et al. The role of ocular muscle proprioception during modifications in smooth pursuit output. Vis Res 1997;37:769-74

55 Weir CR, Knox PC, Murphy P. The effect of impeding one eye on the initiation of smooth ocular pursuit in human subjects. F Physiol 1999;521P:46.

56 Corsi M, Sodi A, Salvi G, et al. Morphological study of extraocular muscle proprioceptor alterations in congenital strabismus. Ophthalmologica 1990; 200:154-63.

57 Mitsui M. The magician's forcepts phenomenon. In: Strabismus and the sensorimotor reflex. Tokyo: Excerpta Medica, 1986:3-17.

58 Optican LM, Zee DS. A hypothetical explanation for congenital nystagmus. Biol Cybern 1984;50:119-34.

59 Dell'Osso LF, Hertle RW, Williams RW, et al. A new surgery for congenital nystagmus: effects of tenotomy on an achiasmatic canine and the role of extraocular proprioception. F Aapos 1999;3:166-82.

60 Keller EL, Robinson DA. Absence of a stretch reflex in extraocular muscles of the monkey. F Neurophysiol 1971;34:908-19.

61 Guthrie BL, Porter JD, Sparks DL. Corollary discharge provides accurate eye position information to the oculomotor system. Science 1983;221:1193-

62 Ludvigh E. Control of ocular movements and visual interpretation of the enviroment. Arch Ophthalmol 1952;48:442-8.

63 Mon-Williams M, Tresilian JR. A framework for considering the role of afference and efference in the control and perception of ocular position. Biol Cybern 1998;79:175-89. 